\title{
SEPARATION OF SIALYL-OLIGOSACCHARIDES BY MEDIUM PRESSURE ANION-EXCHANGE CHROMATOGRAPHY ON MONO Q ${ }^{\circledR *}$
}

Johlannes van Pelt, Jan B. L. Damm, Johannis P. Kamerding, and Johannes F. G. Vliegenthart Department of Bio-Organic Chemistry, Transitorium III, Utrecht University, P.O. Box 80.075, NL-3508 TB Utrecht (The Netherlands)

(Received December 1st, 1986; accepted for publication in revised form, April 17th, 1987)

\section{ABSTRACT}

On columns prepacked with the recently introduced anion-exchange material, Mono $\mathrm{Q}^{\otimes}$ (Pharmacia), sialyl-oligosaccharides could be fractionated excellently according to the sialic acid content. With u.v. absorption at $214 \mathrm{~nm}$ as the detection method, analytical runs of carbohydrate material on the microgram scale, were possible. The value of the method for preparative purposes was demonstrated for sialic acid-containing carbohydrates obtained from human serotransferrin by hydrazinolysis.

\section{INTRODUCTION}

Carbohydrate chains containing sialic acid form an integral part of many glycoconjugates and also occur free in physiological fluids and tissues ${ }^{1}$. Accumulation of sialyl-oligosaccharides has been observed in case of some lysosomal storage disease $^{2}$ and during pregnancy ${ }^{3-5}$.

In the framework of structural analysis of such compounds, their isolation and purification are essential steps ${ }^{6}$. As chromatographic techniques, gel filtration, paper chromatography, paper electrophoresis, low-pressure anion-exchange chromatography, and high-performance liquid chromatography using amino modified silica and anion-exchange resins have been applied ${ }^{7-9}$. The recent introduction of a new type of high-performance anion-exchange resin, Mono $Q^{\circledast}$ (Pharmacia), prompted us to evaluate the suitability of this material with respect to the separation of sialyl-oligosaccharides. Here we present the results for a variety of substances obtained from sialidosis urine and by hydrazinolysis of human serotransferrin.

\section{EXPERIMENTAL}

Preparation of sialyl-oligosaccharides. - Mono-, di-, and tri-sialyl-oligosaccharides related to $\mathrm{N}$-glycosylated proteins were isolated from urine of the

*Dedicated to Dr. R. Stuart Tipson. 


\section{TABLE I}

\section{LIST OF CARBOHYDRATE STRUCTURES INVESTIGATED}

\section{Abbre- Structure}

viation

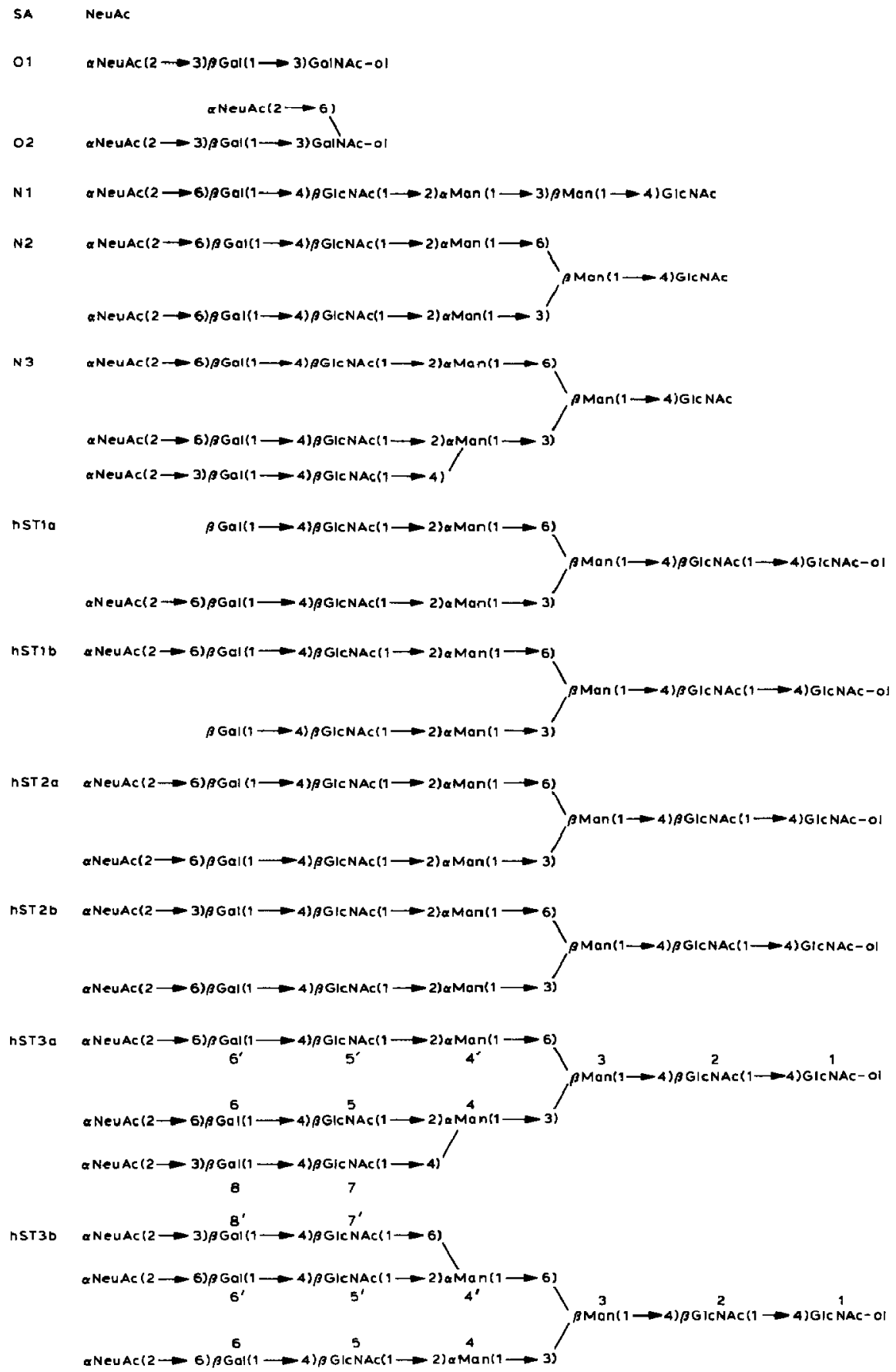


Dutch sialidosis patient E.V. (unpublished results). The ${ }^{1}$ H-n.m.r. data match exactly those reported for the same oligosaccharides, isolated from the sialidosis urine of other patients ${ }^{10}$. The $O$-glycosylic type of mono- and di-sialyl-oligosaccharide-alditols were obtained by alkaline borohydride degradation of glycopeptides, isolated from the urine of the same patient ${ }^{11}$. The ${ }^{1}$ H-n.m.r. data of these compounds are identical to those of $\kappa$-casein ${ }^{12}$. From human serotransferrin (hST) the $\mathrm{N}$-glycosylic type of mono-, di-, and tri-sialyl-oligosaccharide-alditols were obtained via the hydrazinolysis procedure ${ }^{13}$. For a survey of structures, see Table I.

Hydrazinolysis procedure for human serotransferrin. - Hydrazinolysis was performed essentially as described by Kobata et al. ${ }^{13}$. Briefly, the thoroughly dried hST (100 mg) (Sigma) was suspended in $1 \mathrm{~mL}$ of anhydrous hydrazine (Pierce) and heated for $20 \mathrm{~h}$ at $100^{\circ}$. After evaporation of hydrazine, the released carbohydrate chains were re- $N$-acetylated and reduced. The reduced carbohydrate material was desalted on a column $(50 \times 1 \mathrm{~cm})$ of Bio-Gel P-2 (200-400 mesh) using distilled water.

Medium-pressure anion-exchange chromatography. - Anion-exchange chromatography was performed on a Pharmacia Fast Protein Liquid Chromatography apparatus, equipped with a Liquid Chromatography Controller LCC-500 and two P-500 pumps. Separations were achieved at room temperature on an analytical prepacked Mono Q HR 5/5 column $(50 \times 5 \mathrm{~mm})$ (Pharmacia) with a bed volume of $1 \mathrm{~mL}$. The resin, consisting of monodisperse $9.8 \mu \mathrm{m}$ particles, is a strong anion-exchanger with $-\mathrm{CH}_{2}-\mathrm{+}\left(\mathrm{CH}_{3}\right)_{3}$ charged groups.

For the fractionation of the oligosaccharides and oligosaccharide-alditols obtained from sialidosis urine, a linear gradient from $0-100 \mathrm{~mm} \mathrm{NaCl}$ (Merck) in water $(10 \mathrm{~mL})$ of chromatographic quality (Lichrosob, Merck) with a pressure of $2.4 \mathrm{MPa}$ and a flow rate of $2 \mathrm{~mL} / \mathrm{min}$ was applied. Before and after the applied gradient, the column was washed with $2 \mathrm{~mL}$ of water and $2 \mathrm{~mL}$ of $100 \mathrm{mM} \mathrm{NaCl}$, respectively. The eluate was monitored at $214 \mathrm{~nm}$ using a Pharmacia UV-1/214 detector operating at 0.1 absorption unit full scale (AUFS) sensitivity, connected to a dual-chart recorder. Before use, the solvents and the carbohydrate samples were filtered through $0.22 \mu \mathrm{m}$ filters (Millipore). Injection volumes were $50 \mu \mathrm{L}$.

The oligosaccharide-alditols prepared from serotransferrin were fractionated with a linear gradient from $0-10 \mathrm{~mm} \mathrm{NaCl}$ in $10 \mathrm{~mL}$ of water, followed by a steeper gradient from $10-100 \mathrm{mM} \mathrm{NaCl}$ in $9 \mathrm{~mL}$ of water. In this case the u.v. detector operated at 2.0 AUFS and the injection volume was $500 \mu \mathrm{L}$.

500-MHz ${ }^{1} H$-n.m.r. spectroscopy. - Prior to ${ }^{1} \mathrm{H}$-n.m.r. spectroscopic analysis, oligosaccharide-alditols prepared from human serotransferrin and fractionated on Mono $Q$ were repeatedly treated with $\mathrm{D}_{2} \mathrm{O}(99.96$ atom $\% \mathrm{D}$, Aldrich) at $\mathrm{pD} 7$, at room temperature with intermediate lyophilisation. The 500MHz ${ }^{1}$ H-n.m.r. spectra were recorded with a Bruker WM-500 spectrometer (SON hf-n.m.r. facility, Department of Biophysical Chemistry, University of Nijmegen, The Netherlands) operating in the F.t. mode at a probe temperature of $27^{\circ}$. Resolution enhancement of the spectra was achieved by Lorentzian-to-Gaussian 
transformation ${ }^{14}$. Chemical shifts $(\delta)$ are expressed in p.p.m. downfield from internal sodium 4,4-dimethyl-4-silapentane-1-sulfonate, but were actually measured by reference to internal acetone $(\delta 2.225)$ with an accuracy of 0.002 p.p.m. ${ }^{14}$.

RESULTS

For the fractionation on Mono $Q$ of carbohydrate chains containing sialic acid, the neutral solvent-system containing merely $\mathrm{NaCl}$ in water was found to be the most satisfactory, although this eluant has no buffer capacity. A solution of $100 \mathrm{~mm} \mathrm{NaCl}$ has an absorbancy of 0.01 at $214 \mathrm{~nm}$, whereby the gradient to $100 \mathrm{~mm}$ $\mathrm{NaCl}$ causes a baseline drift of about $10 \%$ full scale at the 0.1 AUFS setting.

The separation of the $\mathrm{N}$-glycosylic type sialyl-oligosaccharides $\mathrm{N} 1, \mathrm{~N} 2$, and $\mathrm{N} 3$ (Table I) isolated from sialidosis urine using a linear gradient from $0-100 \mathrm{~mm}$ $\mathrm{NaCl}$ in $10 \mathrm{~mL}$ of water is presented in Fig. 1. The various compounds differ in the number of sialic acid residues and in branching pattern. The separation of the $O$ glycosylic type oligosaccharide-alditols $\mathrm{O} 1$ and $\mathrm{O} 2$ (Table I) obtained by alkaline borohydride treatment of glycopeptide material from sialidosis urine is depicted in Fig. 2. The tri- and tetra-saccharides $\mathrm{O} 1$ and $\mathrm{O} 2$ differ only in one sialic acid residue. As is evident from Figs. 1 and 2, excellent separations are possible within $8 \mathrm{~min}$ based on the number of sialic acid residues. A linear relationship exists between the amount of carbohydrate injected and the resulting absorbance at 214

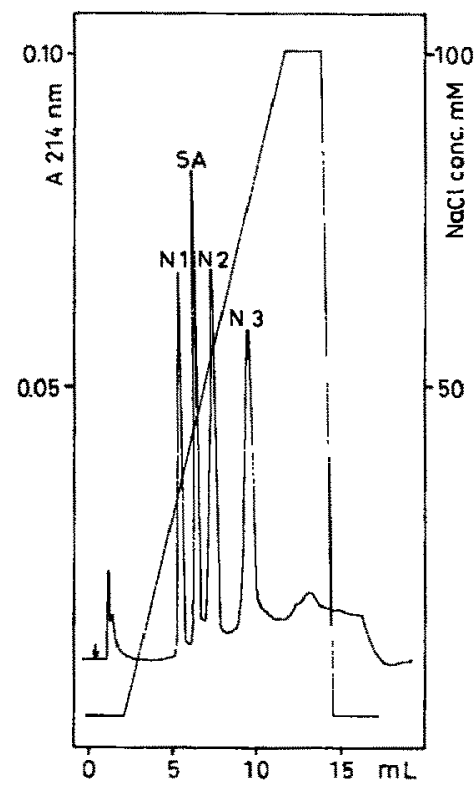

Fig. 1. Separation of $N$-glycosylic complex-type sialyl-oligosaccharides on a Mono Q HR 5/5 anionexchange column $(50 \times 5 \mathrm{~mm})$ with a linear gradient from $0-100 \mathrm{mM} \mathrm{NaCl}$ in $10 \mathrm{~mL}$ of water. Pressure. $2.4 \mathrm{MPa}$; fow rate, $2 \mathrm{~mL} / \mathrm{min} ; \mathrm{u} . \mathbf{v}$, detection, $214 \mathrm{~nm}$. 


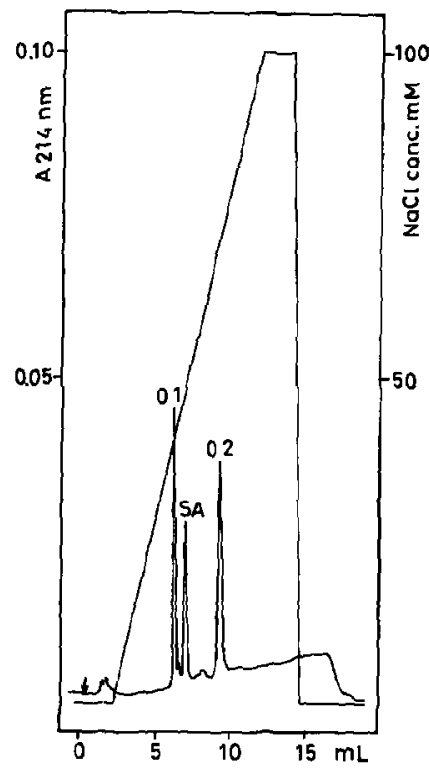

Fig. 2. Separation of $O$-glycosylic sialyl-oligosaccharides on a Mono $Q$ HR $5 / 5$ anion-exchange column $(50 \times 5 \mathrm{~mm})$ with a linear gradient from $0-100 \mathrm{mM} \mathrm{NaCl}$ in $10 \mathrm{~mL}$ of water. Pressure, $2.4 \mathrm{MPa}$; flow rate, $2 \mathrm{~mL} / \mathrm{min}$; u.v. detection, $214 \mathrm{~nm}$.

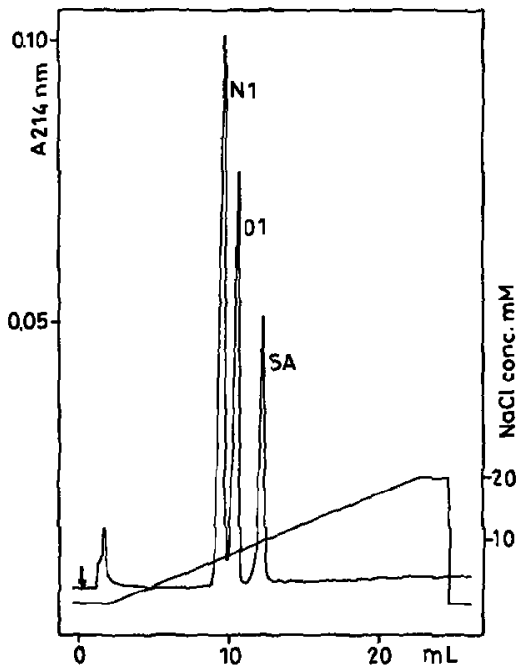

Fig. 3. Separation of the structures $O 1$ and N1 on a Mono $Q$ HR $5 / 5$ anion-exchange column $(50 \times 5$ $\mathrm{mm}$ ) with a linear gradient from $0-20 \mathrm{~mm} \mathrm{NaCl}$ in $20 \mathrm{~mL}$ of water. For additional conditions, see Figs. 1 and 2.

nm. In Fig. 3 the separation of $\mathrm{N} 1$ and $\mathrm{O} 1$ is shown when applying a less-steep slope of the linear gradient. Both compounds are monosialo structures but differ in molecular size.

In Fig. 4 the fractionation pattern is presented of the sialyl-oligosaccharides 


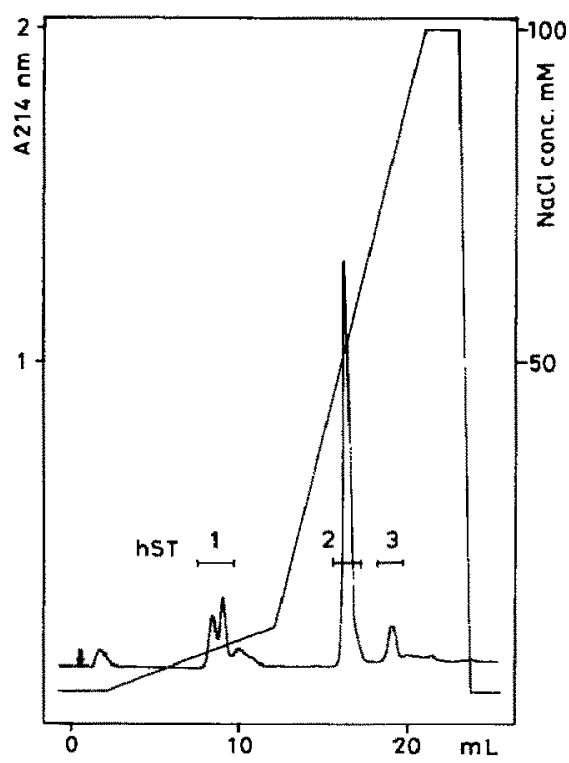

Fig. 4. Separation of the hydrazinolysis products of hST on a Mono $Q$ HR $5 / 5$ anion-exchange column $(50 \times 5 \mathrm{~mm})$ with a linear gradient from $0-10 \mathrm{~mm} \mathrm{NaCl}$ in $10 \mathrm{~mL}$ of water, followed by a gradient from $10-100 \mathrm{~mm} \mathrm{NaCl}$ in $9 \mathrm{~mL}$ of water. For additional conditions, see Figs. 1 and 2.

released from serotransferrin. On the basis of the results obtained with $\mathrm{N} 1, \mathrm{~N} 2$, and N3, it was anticipated that fractions hST1, hST2, and hST3 would correspond to mono-, di-, and tri-sialyl-types of structures, respectively. For further characterisation the fractions were collected, desalted, and subjected to $500-\mathrm{MHz}$ ${ }^{1}$ H-n.m.r. spectroscopy. The relevant chemical-shift data, together with those of some reference compounds, are compiled in Table II.

The ${ }^{1} \mathrm{H}$-n.m.r. spectrum of fraction hST1 showed the presence of a mixture of the two monosialylated diantennary structures hST1a and hST1b (Table I), both terminated with NeuAc in $\alpha(2 \rightarrow 6)$ linkage to one of the branches. The spectral features of the various residues in the upper and lower branches, including those of the mannotriose unit, are essentially identical to those of the corresponding residues in the diantennary-type glycopeptide structures $\mathbf{A}$ and $\mathrm{B}$ from rabbit serotransferrin ${ }^{14,15}$. The $N, N^{\prime}$-diacetylchitobiitol unit is characterised by the GlcNAc-1 H-2 and NAc and GlcNAc-2 H-1 and NAc signals at $\delta$ 4.240, 2.056, 4.641, and 2.080 , respectively ${ }^{16}$.

The ${ }^{1} \mathrm{H}$-n.m.r. spectrum of fraction hST2 demonstrated the major product, hST2a (Table I), to have a diantennary structure with two NeuAc residues $\alpha(2 \rightarrow 6)$ linked. The typical spectral features, except those of the $N, N^{\prime}$-diacetylchitobiitol unit, match the structural-reporter groups of the glycopeptide structure $\mathrm{C}$, reported for human serotransferrin ${ }^{14,17,18}$. Furthermore, small signals were present at $\delta 1.800$ (NeuAc H-3a) and $\delta 2.758$ (NeuAc H-3e), indicating the presence of NeuAc in $\alpha(2 \rightarrow 3)$ linkage. Based on the accompanying low-intensity signals at $\delta 4.926$ (Man$4^{\prime} \mathrm{H}-1$ ), $\delta 4.574$ (GlcNAc-5' H-1), $\delta 4.548$ (Gal-6' H-1), and $\delta 2.042$ (GlcNAc-5' 


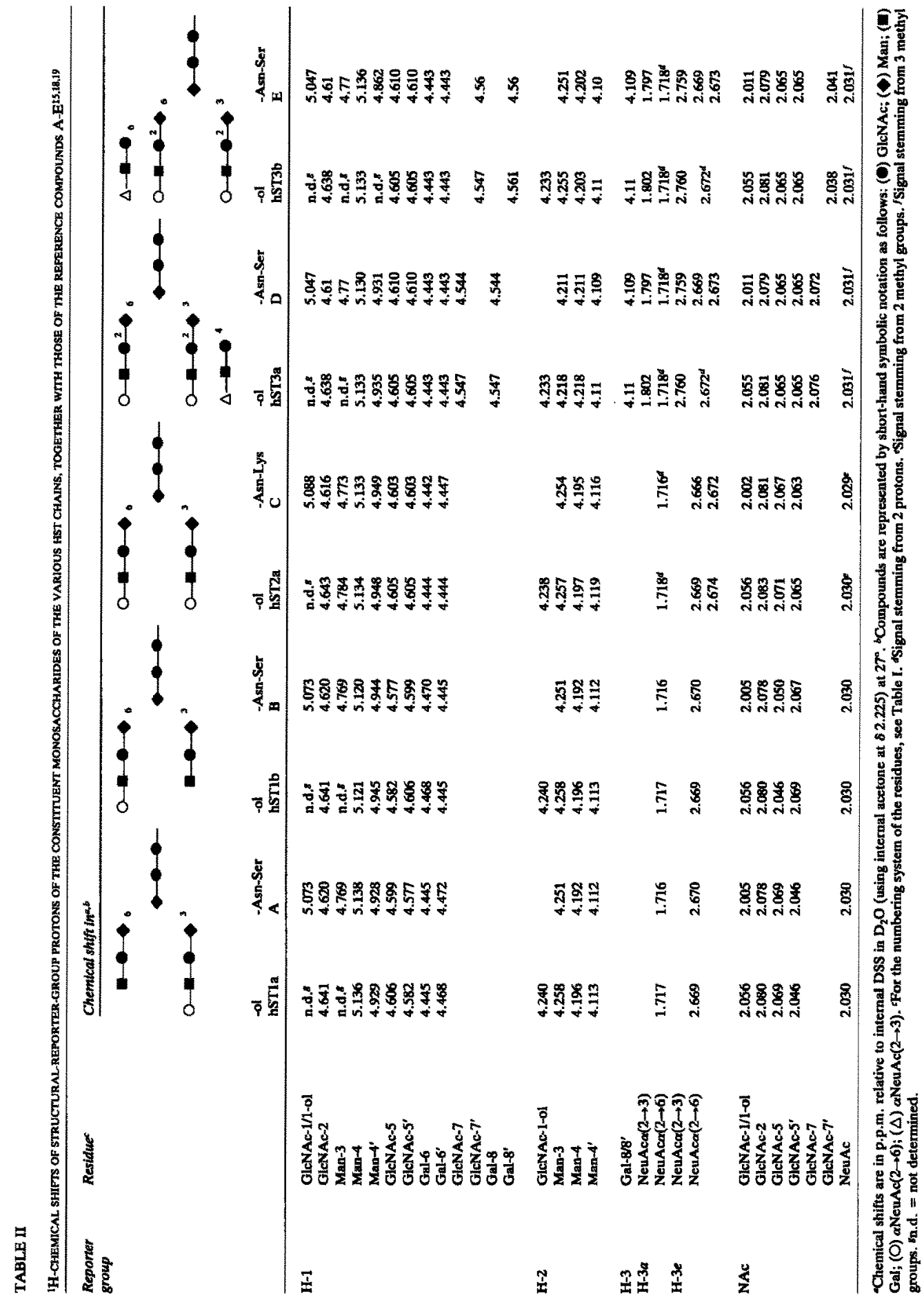


NAc), the latter sialic acid residue is located in the $\alpha \operatorname{Man}(1 \rightarrow 6)$ branch of the minor disialylated diantennary structure hST2b (Table I; see compound 44 in ref. 14). This variant $(5 \%)$ has not been reported before for human serotransferrin preparations. Although the commercial hST used for this study showed a high purity by SDS-gel electrophoresis, it cannot be excluded that the latter variant stems from contaminating serumglycoprotein material.

The ${ }^{1} \mathrm{H}$-n.m.r. spectrum of hST3 pointed to the occurrence of a mixture of the trisialyl-triantennary structures hST3a and hST3b (Table I), in the molar ratio of $\sim 1: 1$. The triantennary structurc hST3a is characterised by the set of chemicalshift values of the Man $\mathrm{H}-1$ and $\mathbf{H}-2$ signals ${ }^{14,19}$. The tri'-antennary structure hST3b is identified by the value of the various Man H-2 signals ${ }^{14,19}$. Both structures bear NeuAc $\alpha(2 \rightarrow 6)$-linked to Gal-6 and Gal-6' as may be deduced from the chemicalshift values of the H-1 signals of the latter residues. Gal-8 in hST3a and Gal-8' in hST3b bear NcuAc in $\alpha(2 \rightarrow 3)$ linkagc, as is evident from the chemical shifts of Gal-8/8' H-1 and GlcNAc-7/7' H-1 and NAc signals. The 'H-n.m.r. data of the glycopeptide analogues $\mathrm{D}$ and $\mathrm{E}$ have been included in Table II for comparison ${ }^{19}$. The isolated and characterised compounds are in full accordance with earlier findings. The same holds for the molar ratio between di- and tri-antennary structures $(17: 3)$ and for the ratio between the two triantennary structures $(1: 1)$.

DISCUSSION

Chromatography over the Mono $Q$ anion-exchange column offers a very fast and reproducible separation method for sialyl-oligosaccharides corresponding with $\mathrm{N}$ - and $\mathrm{O}$-linked carbohydrate chains, occurring in glycoproteins.

The separation is based on the sialic acid content, but the molecular size of compounds having the same number of sialic acid residues has a specific influence on the elution position. This is clear from the elution positions of $\mathrm{N} 1$ and $\mathrm{O} 1$ (Fig. 3 ) and of $\mathrm{N} 2$ and $\mathrm{O} 2$. Obviously, the influence of differences in molecular size on the chromatographic behaviour is most pronounced in relatively small structures. $\mathrm{N}$-Glycosylic carbohydrates differing in one hexose or one $\mathrm{N}$-acetylhexosamine residue are difficult to separate. The eiution profile of the acidic $N$-glycosylic oligosaccharide-alditols obtained by hydrazinolysis and reduction appears to be identical with the profile of the sialidosis sialyl-oligosaccharides, which lack the GIcNAc-1 residue. The analysis of hST carbohydrate chains shows that the use of a Mono $Q$ column is an excellent and convenient alternative for the paper-electrophoresis step, frequently applied in the hydrazinolysis procedure for the separation of neutral and acidic compounds having various numbers of sialic acid residues. The recovery is almost quantitative and the detection is sensitive and direct, which make this technique highly suitable for the analysis of carbohydrate chains of small amounts of glycoproteins.

In conclusion, the incorporation of Mono $Q$ in our analysis strategy for the structure determination of carbohydrate chains from $N$ - and $O$-glycosylproteins and of frec oligosaccharides found in sialidosis urine has proved highly valuable. 


\section{ACKNOWLEDGMENTS}

The authors thank Dr. J. A. van Kuik for recording the ${ }^{1} \mathrm{H}$-n.m.r. spectra. This investigation was supported by the Netherlands Foundation for Chemical Research (SON) with financial aid from the Netherlands Organization for the Advancement of Pure Research (ZWO) and by the Foundation of Clinical Genetics, Rotterdam.

\section{REFERENCES}

1 J. Montreunl, Adv. Carbohydr. Chem. Biochem., 37 (1980) 157-223.

2 M. CANIZ, Cell Biol. Monogr., 10 (1982) 307-320.

3 M. Lemonnier ANd R. BourRiLlon, Carbohyulr. Res., 51 (1976) 99-106.

4 M. Lemonnier, R. BourRIllon, And B. Fournet, Biochem. Biophys. Res. Commun., 77 (1977) 767-774.

5 C. Derappe, C. Bauvy, D. M. Meyer, M. Lemonnifr, M. Lhermtte, and N. Platzer, Carbohydr. Res., 115 (1983) 221-229.

6 E. G. Berger, E. Buddecke, J. P. Kamerling, A. Kobata, J. C. Paulson, and J. F. G. VlIEGENTHART, Experientia, 38 (1982) 1129-1162.

7 S. HoNDA, Anal. Biochem., 140 (1984) 1-47.

8 J. Paz Parente, Y. Leroy, J. Montreull, AND B. Fournet, J. Chromatogr., 288 (1984) 147-155.

9 P. Cardon, J. Paz Parente, Y. Leroy, J. Montreuil. and B. Fournet, J. Chromatogr., 356 (1986) 135-146.

10 L. Dorland, J. Haverkamp, J. F. G. Vliegenthart, G. Strecker, J.-C. Michalski, B. Fournet, G. SpIK, AND J. Montreull, Eur, J. Biochem., 87 (1978) 323-329.

11 J. van Pelt, D. G. J. L. van Bilsen, J. P. Kamerling, and J. F. G. Viuggenthart, Abstr. XIIth Int. Carbohydr. Symp., Ithaca (USA), August 10-15, 1986, p. 261.

12 H. Van Halbeek, L. Dorland, J. F. G. Vliegenthart, A.-M. Flat, and P. Jolles, Biochim. Biophys. Acta, 623 (1980) 295-300.

13 S. TAKasaki, T. MizuochI, and A. Kobata, Methods Enzymol, 83 (1982) 263-268.

14 J. F. G. Vliegenthart, l. Dorland, and H. van Halbeek, Adv. Carbohydr. Chem. Biochem., 41 (1983) 209-374.

15 D. Leger, V. Tordera, G. Spik, L. Dorland, J. Haverkamp, and J. F. G. Vliegenthart, FEBS Lett., 93 (1978) 255-260.

16 J. H. G. M. Mutsaers, J. P. Kamerling, R. Devos, Y. Guisez, W. Fiers, and J. F. G. VliegenTHART, Eur. J. Biochem., 156 (1986) 651-654.

17 G. SpiK, B. Bayard, B. Fournet, G. Strecker, S. Bouquelet, and J. Montreull, FEBS Lett., 50 (1975) 296-299,

18 L. Dorland, J. Haverkamp, B. L. Schut, J. F. G. Vliegenthart, G. Spik, G. Strecker, B. FOURNET, AND J. MONTREUIL, FEBS Lett., 77 (1977) 15-20.

19 G. SPIK, V. Debruyne, J. MontreulL, H. VAN HALbEeK, AND J. F. G. Vliegenthart, FEBS Lett., 183 (1985) 65-69. 